\title{
Longitudinal dynamics and energy analysis for heavy haul trains
}

\author{
Qing Wu $\cdot$ Shihui Luo $\cdot$ Colin Cole
}

Received: 9 April 2014/Revised: 9 June 2014/ Accepted: 13 June 2014/Published online: 3 July 2014

(C) The Author(s) 2014. This article is published with open access at Springerlink.com

\begin{abstract}
Whole trip longitudinal dynamics and energy analysis of heavy haul trains are required by operators and manufacturers to enable optimisation of train controls and rolling stock components. A new technology named train dynamics and energy analyser/train simulator (TDEAS) has been developed by the State Key Laboratory of Traction Power in China to perform detailed whole trip longitudinal train dynamics and energy analyses. Facilitated by a controller user interface and a graphic user interface, the TDEAS can also be used as a train driving simulator. This paper elaborates the modelling of three primary parts in the TDEAS, namely wagon connection systems, air brake systems and train energy components. TDEAS uses advanced wedge-spring draft gear models that can simulate a wider spectrum of friction draft gear behaviour. An effective and efficient air brake model that can simulate air brake systems in various train configurations has been integrated. In addition, TDEAS simulates the train energy on the basis of a detailed longitudinal train dynamics simulation, which enables a further perspective of the train energy composition and the overall energy consumption. To demonstrate the validity of the TDEAS, a case study was carried out on a $120-\mathrm{km}$-long Chinese railway. The results show that the employment of electric locomotives with regenerative braking could bring considerable energy benefits. Nearly $40 \%$ of the locomotive energy usage could be collected from the dynamic brake system. Most of
\end{abstract}

Q. Wu $(\bowtie) \cdot$ C. Cole

Centre for Railway Engineering, Central Queensland University,

Rockhampton, Queensland, Australia

e-mail: q.wu@cqu.edu.au

S. Luo

State Key Laboratory of Traction Power, Southwest Jiaotong University, 610031 Chengdu, China tractive energy was dissipated by propulsion resistance that accounted for $42.48 \%$ of the total energy. Only a small amount of tractive energy was dissipated by curving resistance, air brake and draft gear systems.

Keywords TDEAS - Train simulation - Longitudinal dynamics $\cdot$ Energy $\cdot$ Heavy haul

\section{Introduction}

Heavy haul trains have wide applications all over the world due to their advantages in hauling capability and energy efficiency. A heavy haul train can have hundreds of heavy loaded wagons and can stretch for miles; therefore, the longitudinal dynamics (LTD) issue is inevitable. Meanwhile, the large mass and fast speed of a travelling heavy haul train suggest that enormous energy can be possessed. Take the Chinese Datong-Qinhuangdao railway for example: the gross mass of distributed power (DP) heavy haul trains on this railway has been over 21,000 t each, and the maximum speed has reached $90 \mathrm{~km} / \mathrm{h}$. Trains on the Datong-Qinhuangdao railway are typical of many heavy haul trains, being empty on the return journey after dumping the cargo at the port. The altitude of Datong (mine) is nearly $1 \mathrm{~km}$ higher than that of Qinhuangdao (port). Theoretically, enormous energy can be regenerated from the operation of the Datong-Qinhuangdao railway. Minimising the energy usage for rail transport is significant, but all energy saving measures have to be based on safety. In other words, the boundary condition of energy saving measures must be set so as not to degrade the trains' safety performance. An ideal result is to find some measures that can minimise the energy usage and at the same time can improve the train dynamics performance [1]. Lowering intrain forces can also bring long-term profits as smaller in-train 
forces can alleviate fatigue damage to rolling stock and infrastructure, consequently lowering the maintenance cost.

Train dynamics and energy optimisation measures are required by operators as well as manufacturers. Different routes have different track conditions of grades and curvature, rail condition, etc; also, the rolling stock and train configurations could be different. Therefore, any optimised train control measure or optimised equipment on a specific route should not be simply transplanted to another route, i.e. the optimisation should be customised to the specific route's operational characteristics. The optimisation of LTD and energy usage is a complicated process that requires evaluations of a large number of possible alternatives. The computer simulation of train dynamics and energy usage is the most cost effective approach.

Analyses of both LTD and energy usage of trains have quite reasonably received considerable attention. More than 20 programmes or software packages can be found in the literature for simulations of LTD and/or energy usage. Few software packages (see Table 1) have been reported as being able to perform both LTD and energy simulation, and none reported from China. This article gives an introduction of a state-of-the-art technology named train dynamics and energy analyser/train simulator (TDEAS) developed in China. Firstly, an overview of the TDEAS will be provided. Then, the modelling of wagon connection systems, air brake systems and train energy components in TDEAS will be described. Finally, a case study was carried out on a $120-\mathrm{km}$-long Chinese railway to verify its validity.

\section{An overview of the TDEAS}

The State Key Laboratory of Traction Power (TPL) China, has developed the TDEAS that can be used to perform whole trip LTD and energy analyses. TDEAS uses advanced wedge-spring draft gear models rather than conventional look-up table models, which can simulate a wider spectrum of friction draft gear behaviour. An effective as well as efficient air brake system model has been integrated. The air brake model is able to simulate air brake systems in various train configurations. TDEAS

Table 1 Available technologies

\begin{tabular}{ll}
\hline Technology & Institution \\
\hline CRE-LTS [2] & Centre for Railway Engineering, Australia \\
TOES [3] & Association of American Railroads, USA \\
STARCO [4] & Transportation Technology Center Inc., USA \\
LEADER [5] & New York Air Brake, USA \\
Trip optimizer [6] & GE Transportation, USA \\
TEDS [7] & Sharma \& Associates, Inc., USA \\
\hline
\end{tabular}

simulates the train energy on the basis of a detailed LTD simulation, which enables a further perspective of the train energy composition and the overall energy consumption, as well as the assessment of train safety performance.

TDEAS is facilitated with friendly user interfaces for preprocessing (parameter input) and post-processing (results presentation). It also has a train controller user interface to enable users to control simulated trains and a graphic user interface to display the train status, which means that TDEAS can also be used as a train driving simulator. Three computing languages (Fortran, $\mathrm{C}++$ and $\mathrm{C \#}$ ) have been used in the development of TDEAS so as to take advantage of their individual strong points. The main components of TDEAS are shown in Fig. 1. The primary objective of dividing the kernel programme into an analyser and a simulator is to achieve faster computing performance for the train driving simulator, while more detailed simulation results can still be attained using the analyser with the train control information recorded during the train driving simulation. Note that, though the simulator has higher computing efficiency, the train model in it has not been simplified and is the same as that used with the analyser.

\section{Longitudinal train dynamics modelling}

\subsection{Train modelling}

Modelling of LTD usually assumes that there is no lateral or vertical movement of the vehicles. Based on this

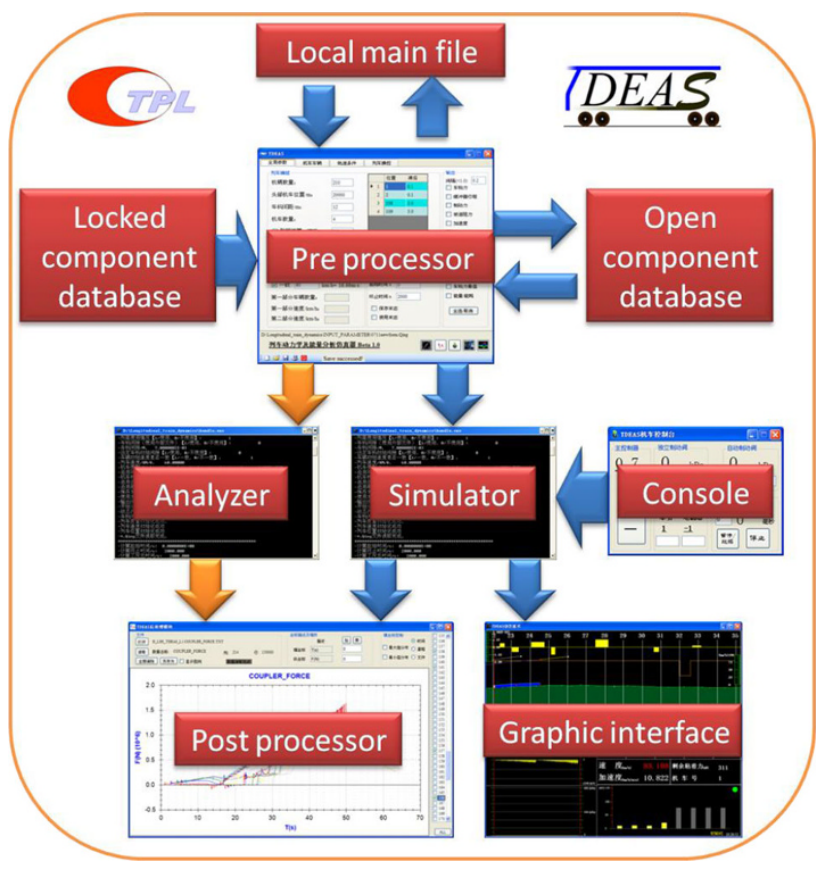

Fig. 1 Main components of TDEAS 
simplification, the forces considered in the train system include traction forces, dynamic brake forces, air brake forces, in-train forces (coupler forces), propulsion resistance, curving resistance and gravitational components. Modelling of the wagon connection systems (in-train forces) and air brake systems (air brake forces) is probably the two most important as well as the most complicated tasks in LTD simulations. This section will only describe the modelling of wagon connection systems and air brake systems. A detailed description of other aspects can be found in [8].

\subsection{Wagon connection system modelling}

All heavy haul wagons in China are using friction draft gears. According to experimental data and published literature $[9,10]$, friction draft gears have friction dependent stiffness and, ultimately, velocity dependent stiffness. The nature of the friction damping gives draft gears non-linear hysteresis and results in discontinuities between loading and unloading curves (Fig. 2). For most cases, smoothing approximations or some transitional characteristics are needed to solve the discontinuity issue mathematically [10]. For the purpose of LTD simulations, wagon connection systems are usually simplified into single-element models, so every two draft gears are modelled in series as a single unit. A unit model of wagon connection system has to incorporate characteristics that can simulate the whole wagon connection system working under both draft and buff conditions. The final model must also consider coupler slack as well as the limiting stiffness that appears after springs are fully compressed. When installed, draft gears are usually pre-loaded, which should also be incorporated. To sum up, a desirable wagon connection dynamics model should include the above discussed elements: velocity dependent friction, slack, limiting stiffness, pre-load and transitional characteristics. The first four elements are usually expressed as force-displacement (F-D) characteristics, so modelling of wagon connection systems has two general aspects, F-D characteristics and transitional characteristics.

Various aspects of draft gear behaviour were identified in [9] by examining measured data. In order to cope with the wide spectrum of draft gear behaviour, a wedge-spring model as shown in Fig. 3 was presented in [9]. This model is a velocity and displacement dependent model, and its FD characteristics can be expressed as Eq. (1).

$F_{\mathrm{c}}=F_{\mathrm{s}}(x) \tan (\theta) /[\tan (\theta)+\mu(v)]$,

where $F_{\mathrm{c}}$ is the draft gear force or coupler force; $x$ is the draft gear deflection; $\theta$ is the wedge angle; $v$ is the relative velocity of adjacent wagons and $\mu$ is the friction coefficient; $F_{\mathrm{s}}$ is the spring force. Note that the spring force can

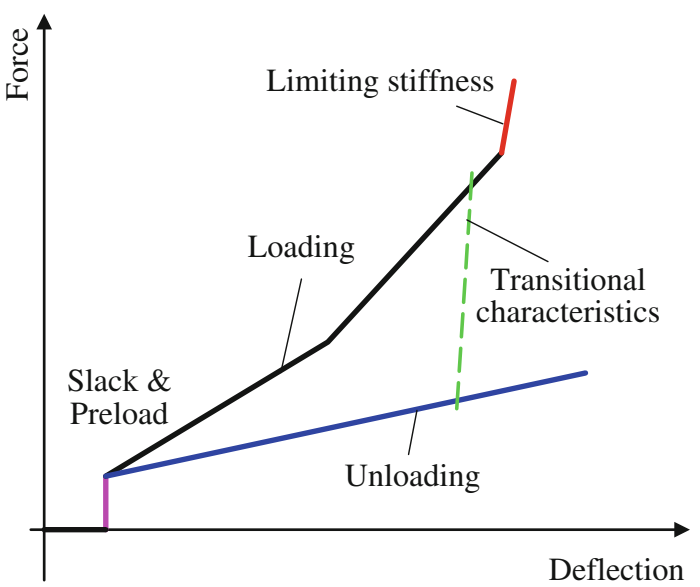

Fig. 2 Wagon connection model

be nonlinear so as to incorporate coupler slack, preload and limiting stiffness [11].

Numerous approaches are available in the literature to handle the discontinuity caused by friction. Basically, they can be divided into the smooth approach [10-13] and the non-smooth approach [14]. Comparatively, the smooth approach is more widely used. In the smooth approach category, there are various sub-approaches. The linear smoothing approach [10] that which imposes an approximation in the range of $\left[-v_{0}, v_{0}\right]$, as shown in Fig. $4\left(v_{0}\right.$ is a predefined constant), is one of the commonly used approaches. In [10], it is pointed out that this traditional smoothing approach will cause considerable errors in the maximum coupler forces. Generally, the maximum coupler forces occur in the vicinity of $v=0$ region of the loading quadrant. Allocating the smoothing range to the loading quadrant (the traditional approach in Fig. 4) could mean that the maximum coupler forces are underestimated. This problem can be alleviated by changing the smoothing range from $\left[-v_{0}, v_{0}\right]$ to $\left[-v_{0}, 0\right]$ as shown in Fig. 4 (the improved approach). Note that the improved approach retains an error in the unloading quadrant, but it is much more insignificant.

TDEAS combines the F-D characteristics model proposed in [9] [Eq. (1)] and the improved transitional characteristics model proposed in [10] (Fig. 4) to model wagon connection systems. Figure 5 is a demonstration of the

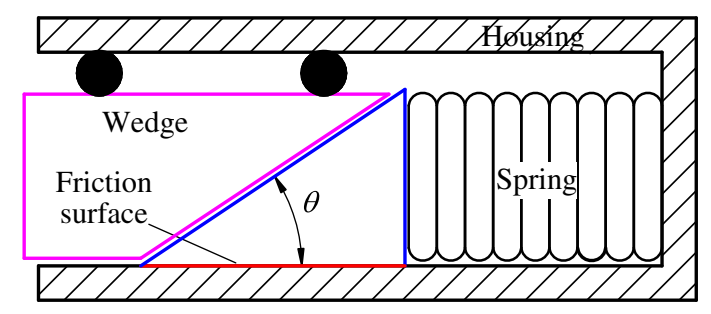

Fig. 3 Wedge-spring draft gear model 


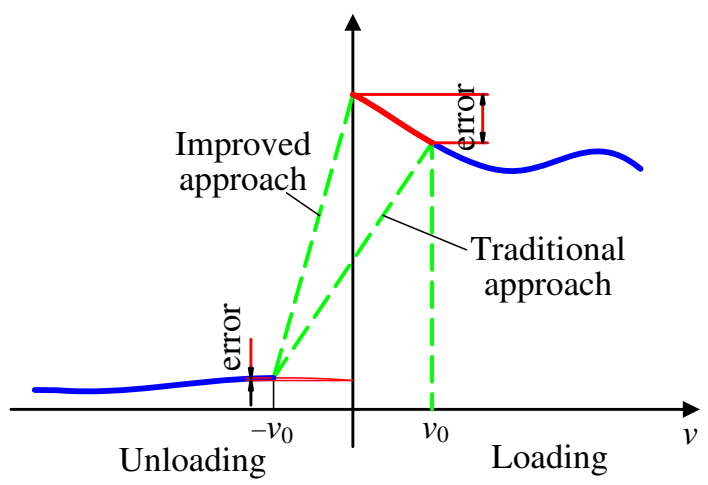

Fig. 4 Improved smoothing approach

wagon connection system model in TDEAS. Figure 5a gives measured data from impact tests; the measured cases were that one loaded wagon weighed $93 \mathrm{t}$ struck the other identical stationary loaded wagon at various velocities on a section of tangent track. Three sequences of data corresponding to the initial velocities of 5,6 and $7 \mathrm{~km} / \mathrm{h}$ are plotted in the form of force-displacement characteristics. Figure $5 \mathrm{~b}$ demonstrates the corresponding simulated results. It can be seen that the simulated results have reached a good overall agreement with the measured results in terms of draft gear behaviour and maximum forces.

\subsection{Air brake system modelling}

When a driver applies train air brakes, the driver's brake valve is opened to exhaust air and gives a pressure reduction in the train brake pipe. The pressure reduction effectively propagates along the pipe, starting at the locomotive and causing a pressure difference between the brake pipe and each wagon auxiliary reservoir. When a sufficient pressure difference exists between the auxiliary reservoir and the brake pipe, the brake valve piston changes its position to connect the auxiliary reservoir and the brake cylinders. The brake pressures reached in brake cylinders are determined by the respective volumes of the auxiliary reservoir and the cylinders as flow continues until the auxiliary pressure equals the cylinder pressures. The pressure reduction of the brake pipe controls the proportion of maximum brake cylinder pressure which is applied. The brake force on each wagon is derived by scaling the brake cylinder pressure through several factors: brake piston area, rigging factor, number of brake shoes and shoe friction coefficient. The friction coefficient of brake shoes is known to be velocity dependent and is calculated from an empirical expression. All the other factors (piston area, rigging, etc.) are determined by the wagon type. Therefore, the most important task for brake force calculations is to obtain the brake cylinder pressures, and for the case of LTD simulation, to obtain the dynamic distribution of brake cylinder pressures along the train during brake application.

Brake cylinder pressures can be calculated by modelling and simulating a fluid dynamic system. Reference [15] has reported detailed air brake system models. The fluid system approach in [15] involves the modelling of various components: brake valves, reservoirs, air compressors, brake pipes, triple valves, etc. It is an accurate approach to study air brake systems and demands considerable computational resources. In order to combine fluid dynamics brake system models with train dynamics models, further simplifications have to be made [16]. Solutions also exist using the results of detailed brake system models indirectly. Firstly, detailed air brake system models were developed and simulated, and then results from the detailed system models were

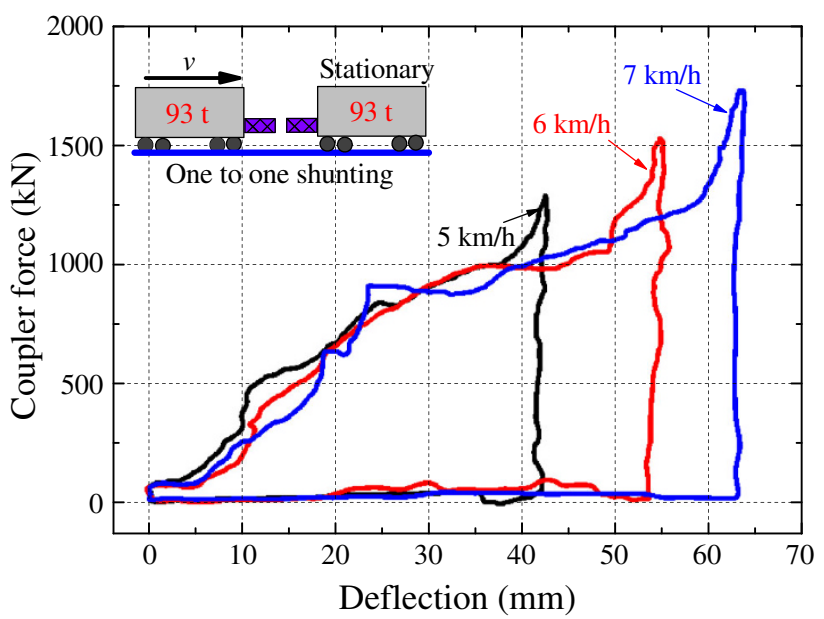

(a)

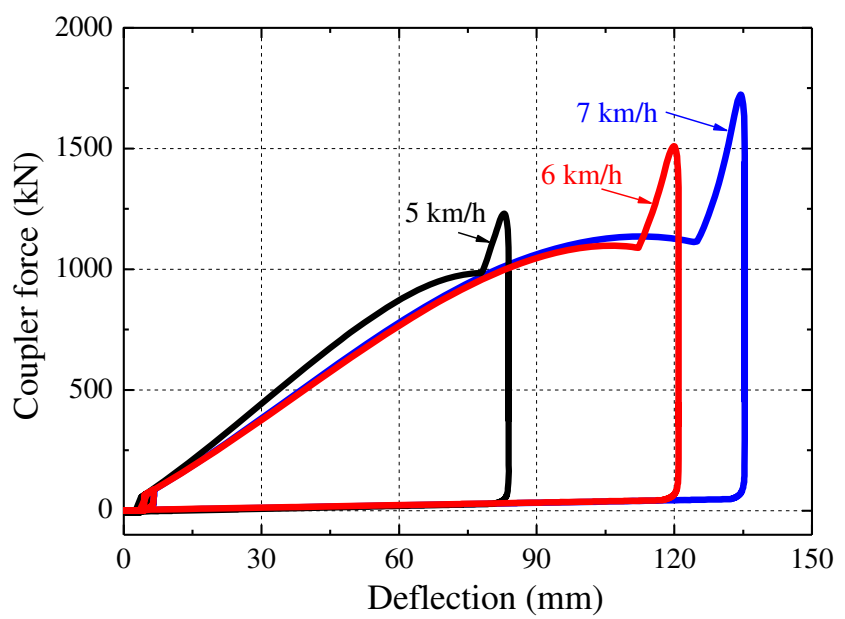

(b)

Fig. 5 Wagon connection system. a Measured results. b Simulated results 


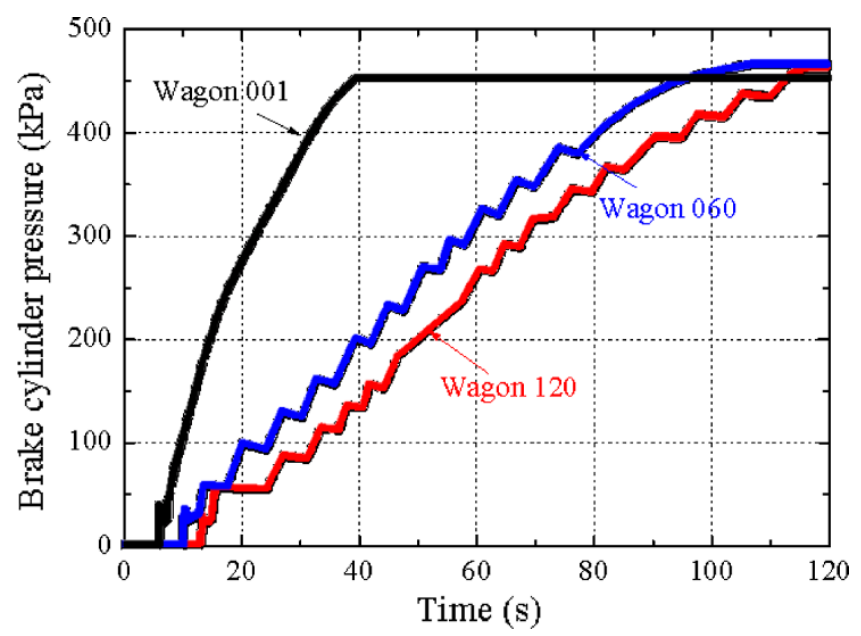

(a)

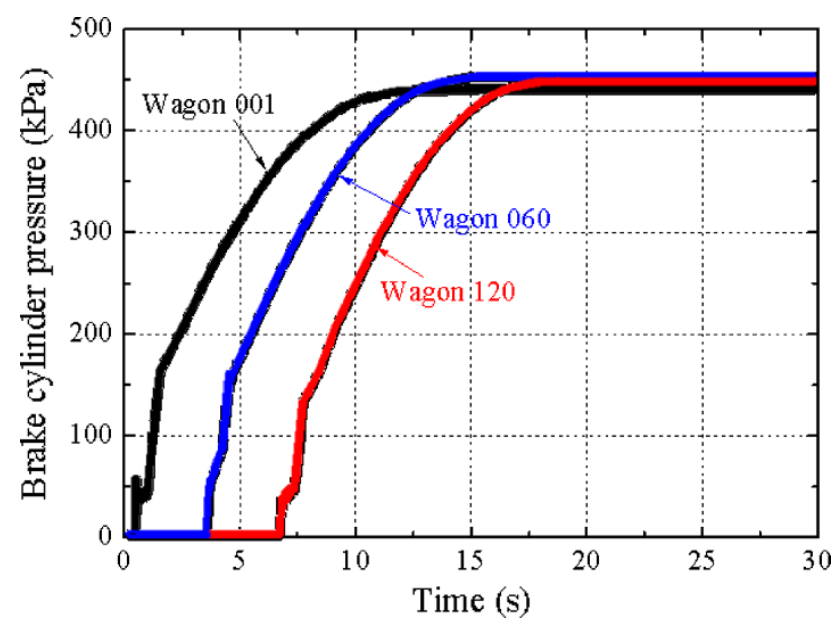

(c)

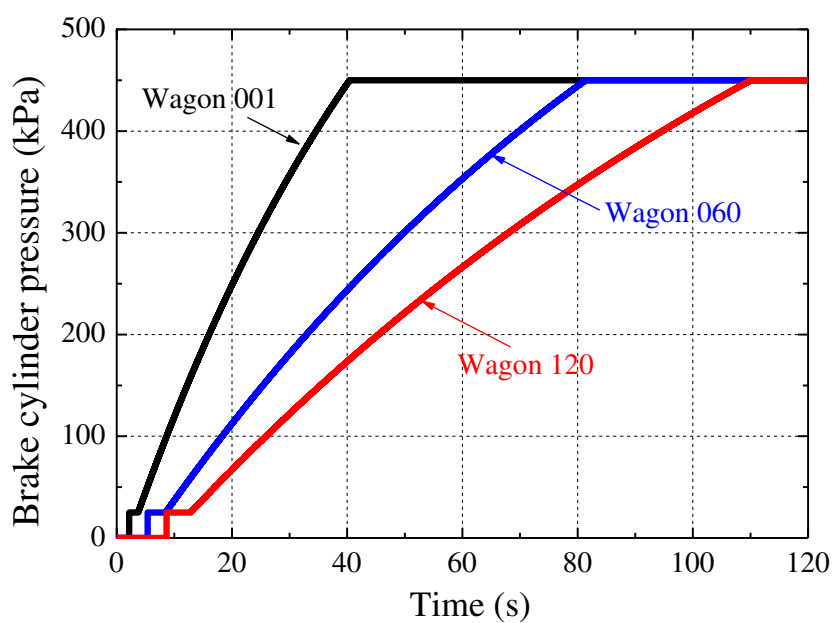

(b)

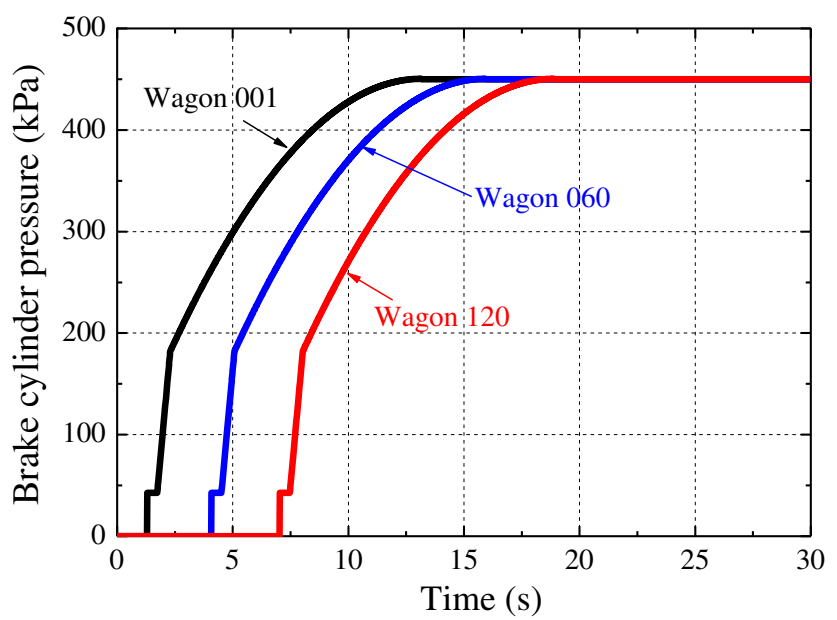

(d)

Fig. 6 Air brake system. a Full-service brake measured results. b Full-service brake simulated results. c Emergency brake measured results. d Emergency brake simulated results

saved in files and used as inputs for train dynamics simulations [17].

Another approach that is computationally efficient and effective from an engineering perspective is to fit the time history of the distribution of brake cylinder pressures along the train $[11,18]$. The fitting approach is also supported by the fact that the brake cylinder pressure is a widely measured parameter in both field and laboratory tests, so the accessibility to source data and their comprehensiveness are good. TDEAS uses the fitting approach to model air brake systems, and the following characteristics are some non-linearities that have been considered:

- The nonlinearity of the propagation speed of brake waves:

$v_{\text {air }}=f_{1}\left(P_{\mathrm{r}}\right)$, where $v_{\text {air }}$ is the propagation speed of brake waves; $P_{\mathrm{r}}$ is the brake signal which indicates the final pressure reduction in brake pipes and $f_{1}$ is the corresponding nonlinear expression.

- The brake delay is associated with the propagation speed of brake waves as well as the train configuration:

$t_{\mathrm{d} i}=\min \left\{t_{\mathrm{dL} j}+\frac{s_{i}-s_{\mathrm{L} j}}{v_{\mathrm{air}}}\right\}\left(j=1, n_{\mathrm{loco}}\right)$,

where $i$ is the wagon sequence number; $t_{\mathrm{d} i}$ is the brake delay of the $i$ th wagon; $j$ is the locomotive sequence number; $n_{\text {loco }}$ is the total number of locomotives in the train; $t_{\mathrm{dL} j}$ is the communication delay of the $j$ th locomotive; $s_{i}$ is the position of the $i$ th wagon on the track; $s_{\mathrm{L} j}$ is the position of the $j$ th locomotive on the track.

- The nonlinearity of the maximum brake cylinder pressure: 


$$
P_{\max }=f_{2}\left(P_{\mathrm{r}}\right),
$$

where $P_{\max }$ is the maximum brake cylinder pressure and $f_{2}$ is the corresponding nonlinear expression.

- The nonlinearity of charging rates of brake cylinders along the train, Eq. (5).

$\beta_{i}=f_{3}\left(P_{\mathrm{r}}, k_{i}\right) \gamma_{i}$,

where $\beta_{i}$ is the parameter used to control brake cylinder charging rates; $k_{i}$ is the interval of the $i$ th wagon to its nearest brake signal source (locomotives or end-of-train devices); $\gamma_{i}$ is the parameter used to modify the charging parameter $\left(\beta_{i}\right)$ for simulations of DP trains and $f_{3}$ is the corresponding nonlinear expression.

- The nonlinearity of the time history of individual brake cylinder pressure. This nonlinearity should include the effects of braking accelerators and movements of brake pistons; both of them can be simulated using boundary conditions. For the non-accelerated part, it can be approximated using exponential functions expressed as

$P_{i t}=P_{\max }\left\{1-\exp \left[-\beta_{i}\left(t-t_{\mathrm{di}}\right)\right]\right\}\left(0 \leq P_{i t} \leq P_{\max }\right)$, where $t$ is the time and $P_{i t}$ is the brake cylinder pressure of the $i$ th wagon at the current time step. Note that the air brake model introduced in this article is generally limited to the specific train configuration and air brake system type from which the fitting data were measured. For different train configurations and brake systems, the equations can be used but the parameters may need to be tuned. It is recommended that all commonly used brake scenarios be included in the final model. Modelling of the brake release and locomotive brake systems can be based on the same framework, although sometimes modifications of mathematical expressions are needed to achieve better accuracy. An example of air brake system fitting is shown in Fig. 6; two cases, i.e. the full-service brake and the emergency brake, are plotted. The measured results were obtained from stationary air brake system test rigs; a 120-car brake system was tested. It can be seen that the simulated results have a good agreement with the measured results in regard to the previously discussed nonlinearities.

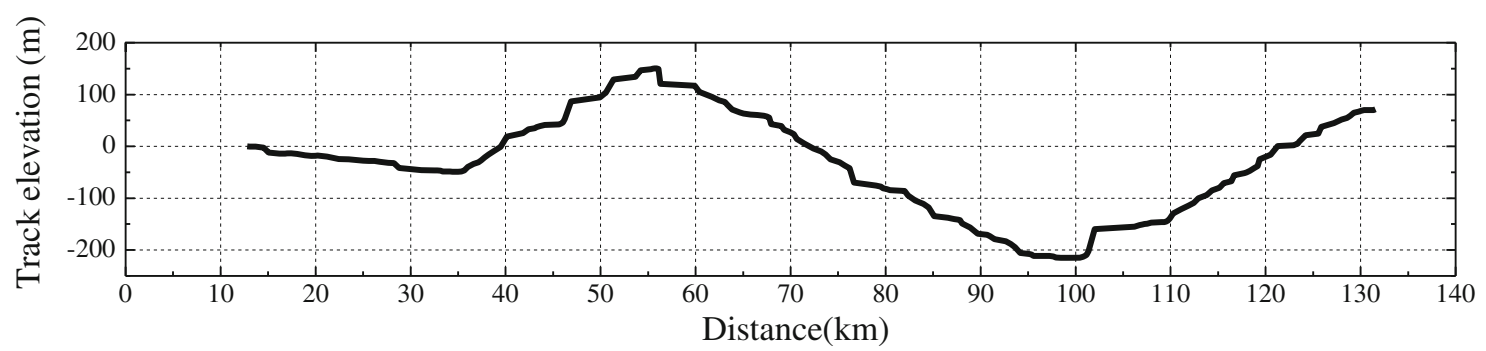

(a)

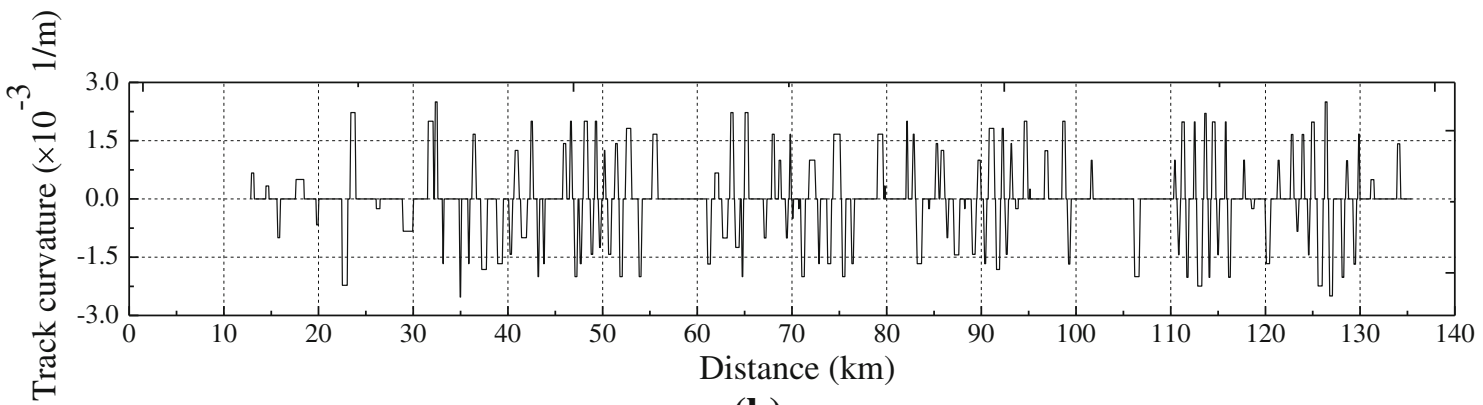

(b)

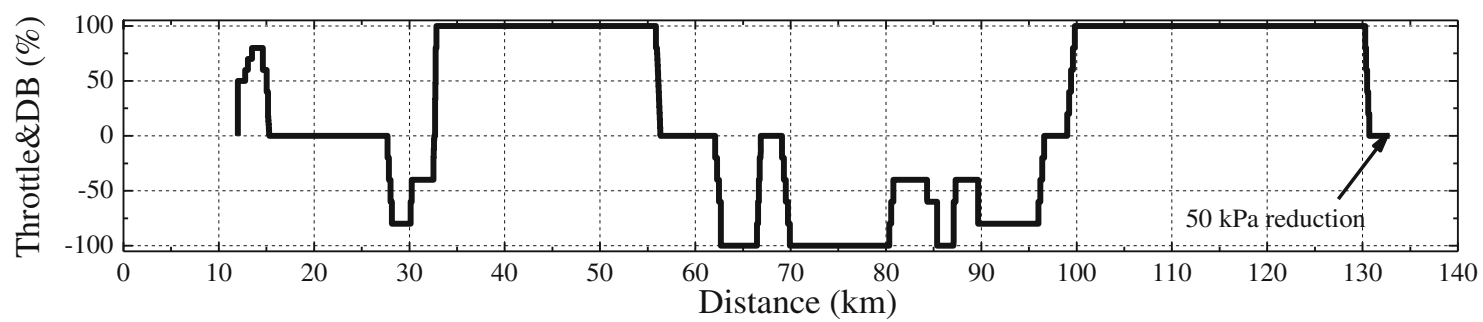

(c)

Fig. 7 Case study inputs. a track elevation. b Track curvature. c Locomotive throttle-DB and train air brake 


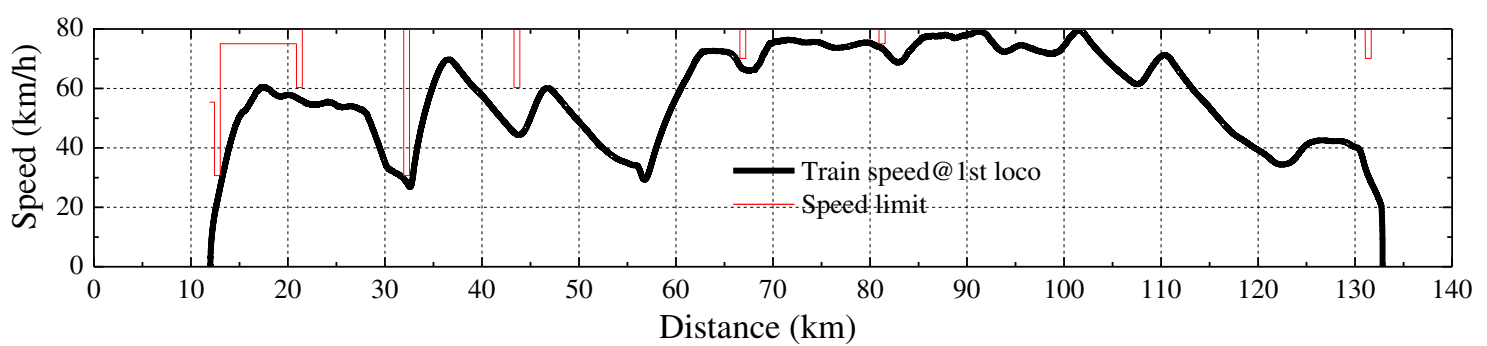

(a)

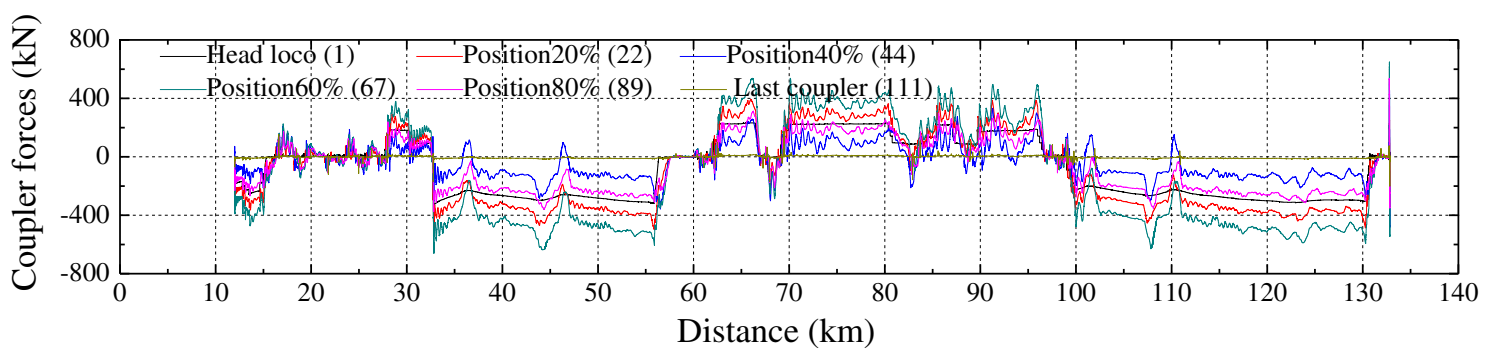

(b)

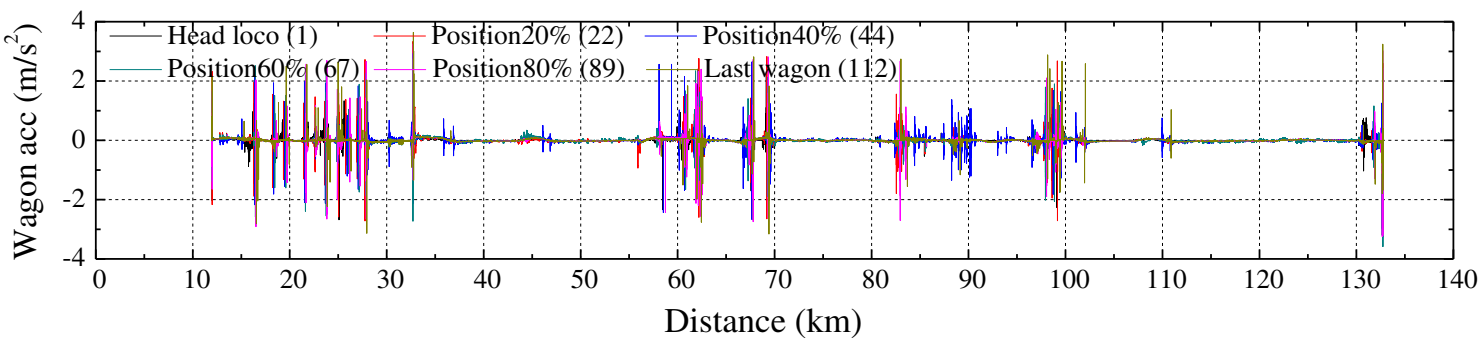

(c)

Fig. 8 Case study outputs. a Speed limit and speed response. b Coupler forces. c Vehicle accelerations

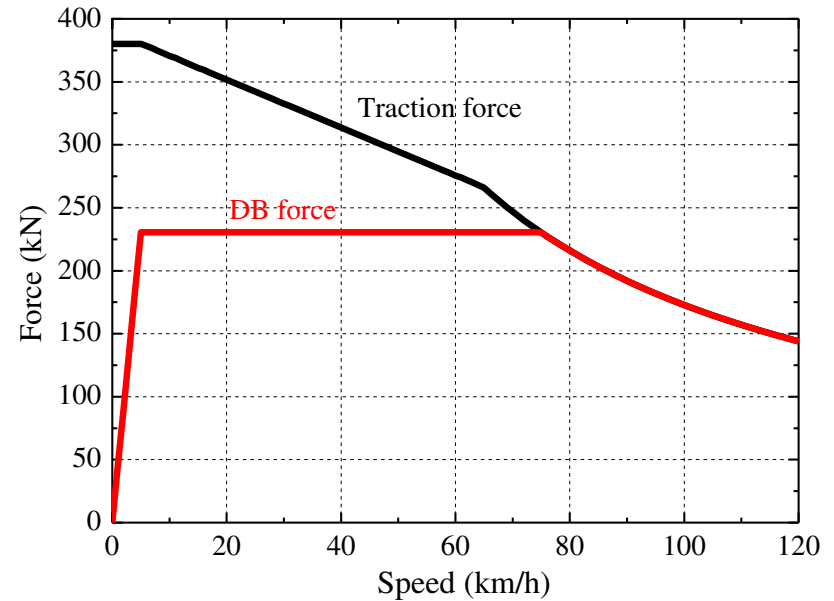

Fig. 9 Locomotive traction and DB forces

\section{Train energy modelling}

The energy issue in train systems is a large topic; a quick understanding of its vast scope can be gained by reference to some major projects, such as Railenergy and TRAINER.
The modelling of train energy in TDEAS is from the perspective of LTD. First, relevant forces, velocities and displacements are obtained via train dynamics simulations; they are then used to calculate various energy components in the train systems.

Eight types of energy components are considered in TDEAS: locomotive energy usage (tractive energy), dynamic brake (DB) related energy (converted into heat or regenerated), energy dissipated by propulsion resistance, gravitational potential energy, energy dissipated by curving resistance, energy dissipated by air brakes, train kinetic energy and energy dissipated by draft gears.

The first six components are calculated using Eq. (7).

$E=\int \sum_{i=1}^{i=n} F_{i} \Delta s_{i} \mathrm{~d} t$

where $E$ is the corresponding energy component; $n$ is the number of vehicles including all wagons and locomotives; $\Delta s_{i}$ is the displacement of the $i$ th vehicle during the current time step and $F_{i}$ is the corresponding force on the $i$ th vehicle. 


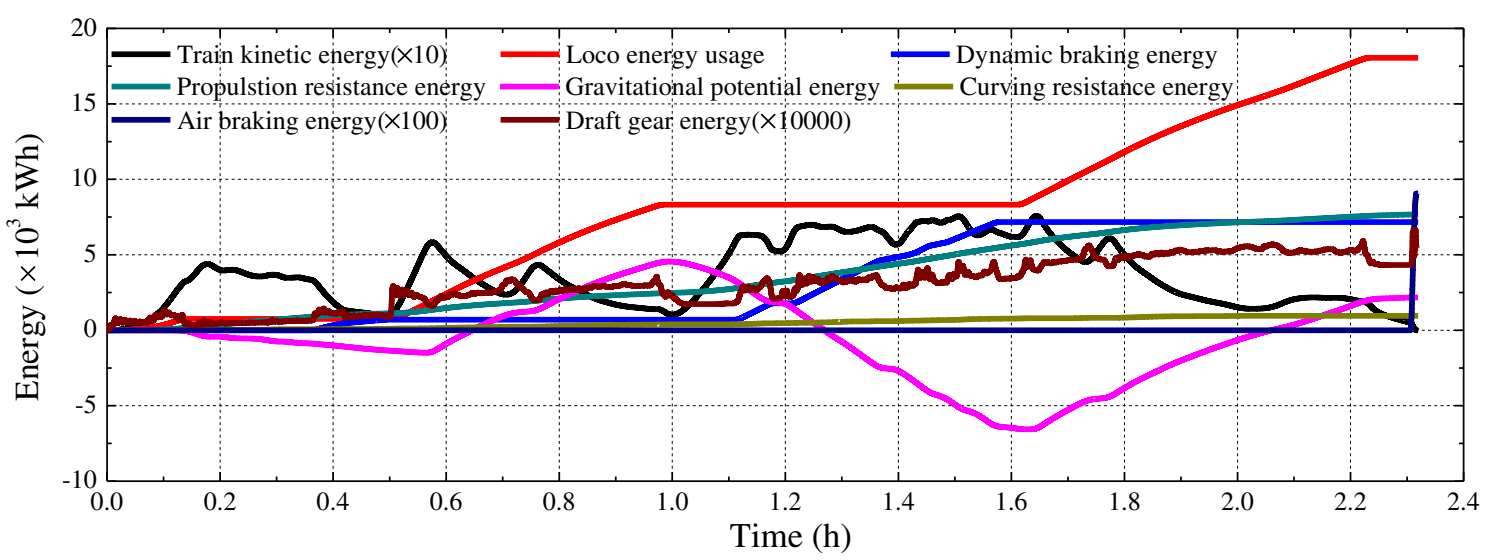

Fig. 10 Time history of various energy components

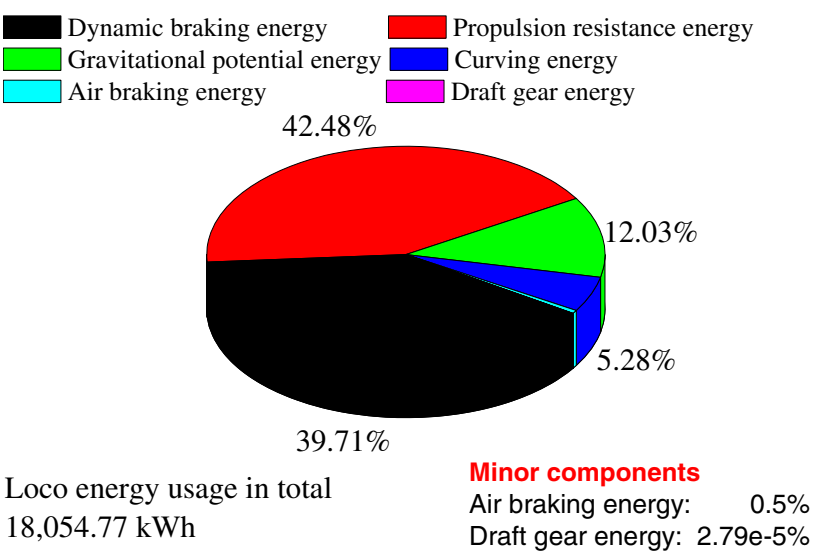

Fig. 11 Composition of energy usage

The kinetic energy is calculated using Eq. (8):

$E=\sum_{i=1}^{i=n} \frac{m_{i} V_{i}^{2}}{2}$,

where $m_{i}$ is the mass of the $i$ th vehicle, and $V_{i}$ is the velocity of the $i$ th vehicle.

A small amount of energy is also dissipated by draft gear devices. Draft gear devices can absorb energy from the train system; they can also release energy to the train system. When calculating the draft gear energy component, draft gear working states, being either loading or unloading, have to be determined. When a draft gear is unloading, a certain amount of energy will be released to the train system, but the released energy should be less than the energy previously absorbed when the draft gear was loading. The energy difference between the loading process and the unloading process is the energy dissipated by the draft gear. The draft gear energy component is calculated using Eq. (9):

$E=\int \sum_{i=1}^{i=n-1} \operatorname{sgn}\left(x_{i} v_{i}\right) \operatorname{abs}\left(F_{\mathrm{c} i} \Delta x_{i}\right) \mathrm{d} t$, where $x_{\mathrm{i}}$ is the deflection of the $i$ th draft gear pair; $v_{\mathrm{i}}$ is the relative velocity of two adjacent vehicles; $F_{\mathrm{c} i}$ is the coupler force; $\Delta x_{i}$ is the deflection change of the $i$ th draft gear pair during the current time step.

\section{Case study}

\subsection{Railway and train information}

In the case study, a Chinese railway was selected. The railway is about $120 \mathrm{~km}$ long, and has a maximum grade of two percent and a minimum curve radius of $300 \mathrm{~m}$. The track elevation and track curvature are shown in Fig. 7a and $b$, respectively. The speed limit is plotted in Fig. 8a. As can be seen from the track data, this railway is difficult for heavy haul trains because of the long severe grades. Before 2013, heavy haul trains on this railway were limited to $5,000 \mathrm{t}$ of gross mass. In order to improve the transport capacity on this railway, a 10,000 t class DP train configuration is proposed. The new scheme uses AC electric locomotives and has a configuration of two locomotives +54 wagons +2 locomotives +54 wagons with gross mass of 11,200 . All wagons and locomotives are $25 \mathrm{t}$-axleload four-wheelset vehicles. The wagon connection systems are equipped with friction draft gears and have coupler slack of $9.8 \mathrm{~mm}$. The traction and DB performance of locomotives are shown in Fig. 9.

\subsection{Results and discussion}

The newly proposed heavy haul train configuration was simulated; the train control information was plotted in Fig. 7c. Four locomotives were used to conquer the severe grades; higher traction capability also means higher DB capability for locomotives. During the simulated trip, only the DB was used to correct the train speed. At the end of 
the simulation, a minimum service brake was used to stop the train. Figure 8 gives the dynamics response of the heavy haul train. It can be seen that no speed violation was recorded, and coupler forces and vehicle accelerations were within allowable ranges. Currently, in China, there are no official standards defining LTD performance requirements. In industry, the criterion is set that in-train forces are mostly not larger than $2,250 \mathrm{kN}$ and acceleration not larger than $1 \mathrm{~g}\left(9.8 \mathrm{~m} / \mathrm{s}^{2}\right)$. The simulated results in Fig. 8 are well below these dynamic performance limits. Note that the driving strategy used in this article is merely one possible case; better strategies could exist.

An overview of the time history of various energy components in the simulated train can be gained from Fig. 10. The final composition of energy usage is shown in Fig. 11. As can be seen from Fig. 11, the total locomotive energy usage in the simulated trip was $18,054.77 \mathrm{kWh}$, most of which was dissipated by propulsion resistance, accounting for $42.48 \%$. For this specific route, the utilisation of electric locomotives could bring significant profits. Note that, unlike diesel locomotives that convert the DB energy into heat, electric locomotives could feed the DB energy back to the power supply system. Nearly $40 \%$ of the locomotive energy usage was regenerated through DB in the simulation. This significant figure was contributed by the high DB capability and the severe track grades. About $12 \%$ of locomotive energy usage was converted to gravitational potential energy. Only approximately $5 \%$ and $0.5 \%$ were dissipated by curving resistance and air brake forces, respectively. The extremely small percentage for draft gear energy $(2.79 \mathrm{e}-5 \%)$ indicates that, from a long-term perspective, the energy dissipated by draft gear systems is minimal.

\section{Conclusion}

The TDEAS developed by TPL can be used to perform whole trip LTD and energy analysis as well as act as a driving simulator for heavy haul trains.

Whole trip simulations are necessary for heavy haul train operations not only for the longitudinal dynamics concerns but also for the energy issue. Longer, heavier and faster trains mean more complicated train dynamics behaviour and larger energy usage. Good driving strategies can not only decrease the energy usage to increase profits directly, but also decrease the fatigue damage, thus resulting in reduced maintenance costs.

Different routes have different track conditions; the rolling stock and train configurations could also be different. Any optimised train control measure or optimised equipment on a specific route should not be simply transplanted to another route. In the case study, the employment of electric locomotives with regenerative braking could bring considerable energy benefits. Nearly $40 \%$ of the locomotive energy usage can be collected from the DB system. From a long-term perspective, the energy dissipated by draft gear systems is minimal.

Acknowledgments This work was done at State Key Laboratory of Traction Power in China. The authors are grateful to the Centre for Railway Engineering for providing the time and support for writing this article. The first author is the recipient of an International Postgraduate Award (IPRA) and University Postgraduate Research Award (UPRA), Central Queensland University, Australia.

Open Access This article is distributed under the terms of the Creative Commons Attribution License which permits any use, distribution, and reproduction in any medium, provided the original author(s) and the source are credited.

\section{References}

1. McClanachan M, Cole C (2012) Current train control optimization methods with a view for application in heavy haul railways. Proc Inst Mech F J Rail Rapid Transit 226(1):36-47

2. Sun Y, Cole C, Spiryagin M, Godber T, Hames S, Rasul M (2014) Longitudinal heavy haul train simulations and energy analysis for typical Australian track routes. Proc Inst Mech F J Rail Rapid Transit 228(4):355-366

3. Klauser PE (1988) Advances in the simulation of long train longitudinal dynamics. Veh Syst Dyn 17(s1):210-214

4. Transportation Technology Center, Inc (2001) Technical manual: simulation of train action to reduce cost of operations (STARCO). Transportation Technology Center, Pueblo

5. Michael J. Hawthorne (2009) LEADER's evolution to train control. In: Proceedings of the 9th international heavy haul conference, Shanghai (China). China Railway Publishing House, Beijing, pp 728-733, 22-24 June 2009

6. Houpt P, Bonanni P, Chan D, Chandra R, Kalyanam K, Sivasubramaniam M, Brooks J, McNally C (2009) Optimal control of heavyhaul freight trains to save fuel. In: Proceedings of the 9th international heavy haul conference, Shanghai (China). China Railway Publishing House, Beijing, pp 1033-1040, 22-24 June 2009

7. Andersen DR, Booth GF, Vithani AR, Singh SP, Prabhankaran A, Stewart MF, Punwani SK (2012) Train energy and dynamics simulator (TEDS)-a state-of-the-art longitudinal train dynamics simulator. In: Proceedings of the ASME 2012 rail transportation division fall technical conference (RTDF2012), Omaha (USA). American Society of Mechanical Engineers 2012, 16-17 Oct 2012

8. Cole C (2006) Longitudinal train dynamics. In: Iwnicki S (ed) Handbook of railway vehicle dynamics. Taylor \& Francis, London, pp 239-278

9. Cole C (1998) Improvements to wagon connection modelling for longitudinal train simulation. In: Conference on railway engineering proceedings: engineering innovation for a competitive edge, Rockhampton, Australia. Central Queensland University, Rockhampton 1998, pp 187-194, 7-9 Sept 1998

10. Qi Z, Huang Z, Kong X (2012) Simulation of longitudinal dynamics of long freight trains in positioning operations. Veh Syst Dyn 50(9):1049-1433

11. Wu Q, Cole C, Luo SH (2013) Study on preload of draft gear in heavy haul trains. Paper presented at the 23th international 
symposium on dynamics of vehicles on roads and tracks (IAVSD), Qingdao, China, 19-23 Aug 2013

12. Wu Q, Cole C, Luo S, Spiryagin M (2014) A review of dynamics modelling of friction draft gear. Veh Syst Dyn 52(6):733-758

13. Wu Q, Luo S, Xu Z, Ma W (2013) Coupler jackknifing and derailments of locomotives on tangent track. Veh Syst Dyn 51(11):1784-1800

14. Oprea RA, Cruceanu C, Spiroiu MA (2013) Alternative friction models for braking train dynamics. Veh Syst Dyn 51(3):460-480

15. Wei W, Lin Y (2009) Simulation of a freight train brake system with 120 valves. Proc Inst Mech F J Rail Rapid Transit 223(1):85-92
16. Belforte P, Cheli F, Diana G, Melzi S (2008) Numerical and experimental approach for the evaluation of severe longitudinal dynamics of heavy freight trains. Veh Syst Dyn 46(S1):937-955

17. Pugi L, Rindi A, Ercole AG, Palazzolo A, Auciello J, Fioravanti D, Ignesti M (2011) Preliminary studies concerning the application of different braking arrangements on Italian freight trains. Veh Syst Dyn 49(8):1339-1365

18. Nasr A, Mohammadi S (2010) The effects of train brake delay time on in-train forces. Proc Inst Mech F J Rail Rapid Transit 224(6):523-534 